\title{
The Effectiveness of a CLIL Basketball Lesson: A Case Study of Japanese Junior High School CLIL
}

\author{
Yukiko Ito ${ }^{1}$ \\ ${ }^{1}$ Faculty of Management, Osaka Seikei University, Osaka, Japan \\ Correspondence: Yukiko Ito, Faculty of Management, Osaka Seikei University, Osaka, 3-10-62, Aikawa, \\ Higashiyodogawa-ku, Osaka, 533-0007, Japan.
}

Received: September 26, 2019

Accepted: October 20, 2019 Online Published: October 22, 2019

doi: $10.5539 /$ elt.v12n11p42

URL: https://doi.org/10.5539/elt.v12n11p42

\begin{abstract}
This article outlines a junior high school physical education class which teaches basketball in English using the CLIL framework as a case study. The purpose of the article is to consider how and what students learned from the class through students' class results, basketball skills test, post lesson questionnaire and pre and post lesson teacher interviews. It examines how the teacher's attitude toward CLIL changes from pre and post lesson interviews. Through this CLIL class led not by English teachers but by a physical education teacher the qualities and abilities necessary for competent CLIL teaching are considered. Regarding students, this CLIL lesson was conducted for the acquisition of physical basketball skills, English expressions and situational English ability. It also aimed to teach 21 st-century skills defined by global education. The lesson resulted in students being able to understand both the English target structures and the basketball terms and strategies taught. In addition, students not only learned the content of the lesson, but also co-operated well with the teacher and worked well in teams which made the lesson successful. Before the lesson, the teacher felt that the CLIL lesson would be difficult for the students. However, the lesson was well received and had a great effect on the students and the teacher herself gained confidence. The experience they gained will lead to skills that will help them succeed in a global society in the future.
\end{abstract}

Keywords: CLIL (Content and Language Integrated Learning), physical education, basketball, 21st Century skills

\section{Introduction}

When considering how to educate children for future society, it is important for students to acquire skills which enable them to work well together to solve problems which arise. The National Institute for Education Policy Research (2013) indicates that it is important to foster human resources which can respond flexibly to rapidly changing societies while recognizing the Japanese temperament which is hardworking and strives to solve problems harmoniously.

In many countries including Japan, skills are required for children to succeed in the future global society, such as the "key competencies" outlined by the OECD and " $21^{\text {st }}$ century skills" by SCANS (Secretary's Commission on Achieving Necessary Skills). The abilities sought by each country vary; however, they share a common direction. Each country emphasizes basic skills such as language and information, plus general higher-order thinking skills which go beyond individual subjects. Bloom (1956) divides thinking skills into higher-order thinking skills (HOTS) and lower-order thinking skills (LOTS). It was revised by Anderson and Krathwohl later in 2001. HOTS involve analyzing, evaluating and creating while LOTS involve remembering, understanding and applying (Coyle, Hood, \& Marsh, 2010). In addition to thinking skills and language and information, social skills which are acquired in connection with society and culture are given importance.

According to a report done by the Central Education Council in 1996, "Education in Japan looking toward the $21^{\text {st }}$ century" vitality is fostered by finding, learning, thinking, independently judging and acting on issues by oneself. The Course of Study (Ministry of Education, Culture, Sports, Science and Technology, 2017) indicates the importance of practical learning in co-operation with other subjects along with creating an environment in schools which lead to physical fitness. This is consistent with CLIL: by teaching subject content in English it integrates foreign language studies with other subjects. Therefore, in this research we focus on CLIL (Content and Language Integrated Learning), which aims to develop higher-level thinking skills while acquiring language 
skills and learning content from other subjects. The results of CLIL lessons have been confirmed by many researchers (Ito, 2018; Kashiwagi \& Tomecsek, 2015; Yamano, 2013). Furthermore, Sasajima (2011) states that instead of suffering, through CLIL native language improves along with English proficiency. In addition, through CLIL students receive general education: not only learning subject content and foreign language skills, but also developing general-purpose abilities (Ikeda, 2017).

In line with the background outlined above, in this research CLIL classes are carried out, teaching basketball to junior high school students with the aim of improving athletic ability, motivation, English proficiency, and fostering global skills. Through students' class results, basketball skill test, questionnaires and teacher interviews, what the student learned from the classes and how the teacher's attitude toward CLIL changed after the CLIL lessons was examined.

\section{Current Research}

\subsection{Research Purpose}

The purpose of this research is (1) to teach basketball in English using the framework of CLIL to female physical education classes in the second grade of public junior high school and (2) to consider through students' post-class reflection and teacher interviews the following three points: a) the qualities necessary for a CLIL teacher, b) the ideal way to construct and conduct a CLIL class and c) the degree of student's learning as a result of the CLIL class.

\subsection{Research Participants}

The participants in this research are 23 Japanese junior high school second grade girls aged 13 to 14 . Among them, 6 students belong to the girls' basketball club. Each of the participants has had the experience of taking basketball as a P.E. unit during their first year of junior high school and understand the basic movements and rules of basketball. However, the students who are not on the school basketball team are not familiar with offensive and defensive movements or game strategies. Regarding English learning, students received one hour of instruction a week in $5^{\text {th }}$ and $6^{\text {th }}$ grade (about 70 hours in total) based mainly on the "Hi, friends!" English textbook (Ministry of Education, Culture, Sports, Science and Technology, 2012) and will receive 270 hours of instruction throughout the three years of junior high school. Students are confident with English listening exercises, but experience challenges with writing and verbal expression.

The participating teacher is a physical education teacher with 15 years of teaching experience in public junior high schools and has a background in soccer and basketball. Currently she coaches the girls' basketball team. Regarding English ability, she understands daily conversation and can convey what she wants to say in simple English.

\subsection{Research Method}

The research procedure is as follows. The CLIL class was held in February 2018, during the initial part of the P.E. basketball unit. One unit is typically four weeks. Over the course of three one-hour classes, students received instruction in basic movements and game strategy of basketball and played a match. After the class, a post-class reflection questionnaire was distributed to each student. The questionnaire contents included how much they understood the English content of the class and what they learned about basketball. The following is the post-class questionnaire:

Q1 Did you enjoy today's basketball lesson?

Q2 Do you like English classes (as foreign language studies)?

Q3 Did you understand the lesson content in English?

Q4 Do you remember the English terms for basketball moves and skills?

Q5 What did you learn from these basketball lessons?

For Q1 to Q4 students were asked to express their answers according to the Likert scale: 4: strongly agree, 3: agree, 2: disagree, 1: strongly disagree, while for Q5 students were encouraged to write their answers freely.

Two 60-minute pre and post lesson interviews with the teacher were also carried out. These were conducted as semi-structured interviews and asked about class development, results of the lesson, students' reactions to the lesson and the teachers own concerns and expectations about CLIL.

The students' pre and post lesson questionnaires were subjected to text analysis using KH Coder (Higuchi, 2014). This analysis method was chosen as objectivity is emphasized in qualitative analysis. SCAT (Steps for Coding and Theorization) analysis was adopted (Otani, 2011) to analyze data collected from the teacher's interviews. 
The analytical procedure of SCAT consists of the following four coding steps: (1) To isolate words and phrases which should be given special attention. (2) To find words and phrases that can be used as replacements from outside the data (1). (3) To find words and phrases which explain the words in step (1) and (2). (4) To figure out the themes and constructs from step (1), (2) and (3), and construct a theory and a story line. SCAT was adopted as it is effective for single-case analysis data and small-scale qualitative data. After the four weeks basketball lessons, a basketball skills test was conducted included shooting, passing, dribbling, movement, and judgements.

\section{Previous Research}

\subsection{CLIL (Content and Language Integrated Learning)}

In this study, a junior high school physical education class using the CLIL framework was performed. CLIL is a teaching method which focuses on both second language acquisition and content learning (Coyle et al., 2010). It is characterized by $4 \mathrm{Cs}$ : content, communication, cognition and culture/community. CLIL classes are generally constructed based on these 4Cs. "Content" relates to topic or subject, "Communication" is language knowledge and skill, "Cognition" refers to higher and lower thinking skills (HOTS and LOTS), and "Culture/Community" involves collaborative learning and cross-cultural awareness (Sasajima, 2011; Watanabe et al., 2011). CLIL classes require higher-order thinking skills to analyze and create; these thinking skills go beyond lower-order thinking skills such as memorizing and understanding content. Therefore, the focus is on peer-learning and groups who learn together and teach each other.

Ikeda (2018) states that learning is most effective when the brain process at the time of learning matches the brain process that would occur at the time the learned material would be used. Learning based simply on grammar structures and translating English into Japanese is not useful for communication. Since the thinking process in CLIL at the time of learning is the same as it would be during real use, usable English is fostered. While learning a second language through CLIL, input called Teacher Talk in which the teacher speaks to the learner is important, and it is the authentic language which would be used in the actual situation (Muranoi, 2006).

In CLIL, variations such as main purpose, frequency of classes or choice of language used can be flexibly applied depending on the circumstances of the educational environment (Watanabe et al., 2011). There are variations in CLIL as shown in Figure 1 and various types of lessons are possible. In this study, in "subject education", "all of the class" will be conducted "in English" "many times". The checkmarks $(\checkmark)$ indicate the form of the class performed for this research.

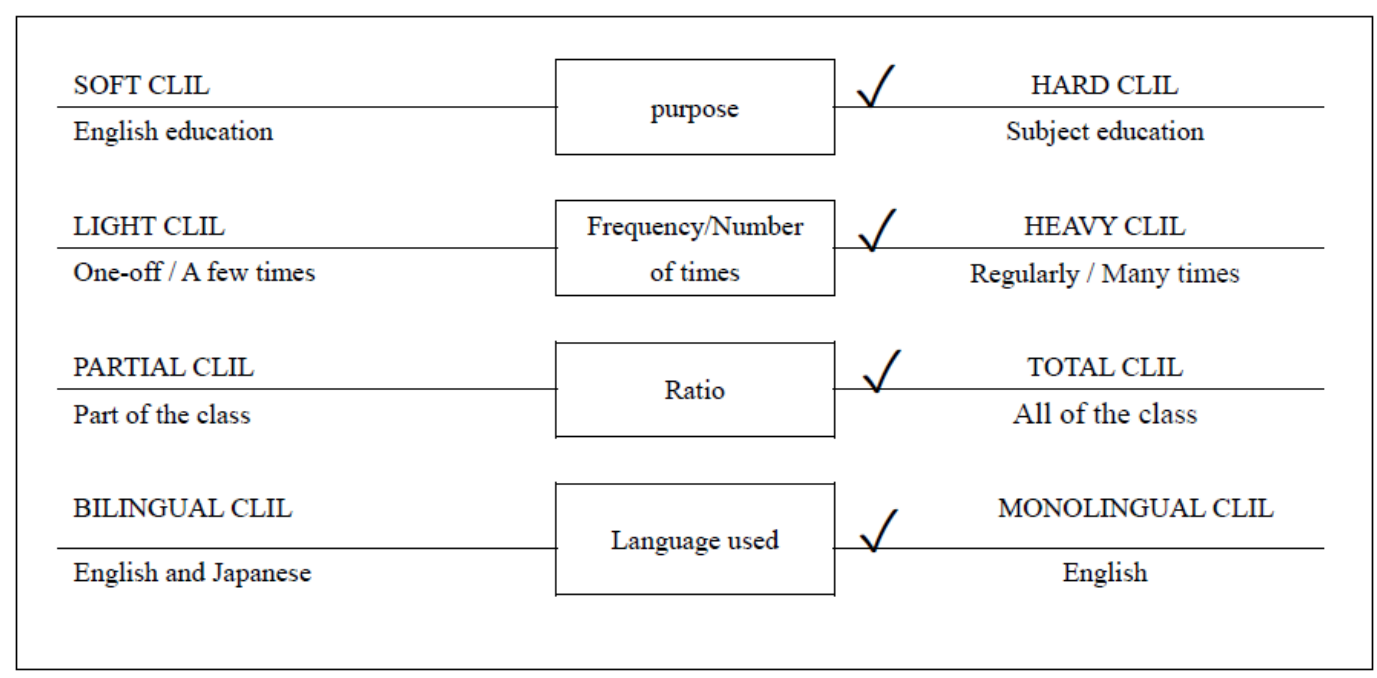

Figure 1. Variations in CLIL (Watanabe et al., 2011:10)

\subsection{Physical Education Instruction (Basketball)}

As shown in the introduction, health, strength and vitality are important and research relating to these is actively conducted across many subjects. Among various educational activities physical education, which aims to develop students' healthy minds and bodies through physical activity, is attracting attention as one of the 
subjects which contributes to vitality (Nishijima et al., 2000). Vitality is related to $21^{\text {st }}$ century skills and research on how physical education can contribute is progressing. Physical Education is essential in that it teaches cooperation, fosters motivation, requires thinking (for example strategy and tactics) and maintains physical fitness. Fujiwara (2013) states that the ball games taught within the junior high school physical education department are classified into three types: "goal type", "net type" and "baseball type". Basketball, which is a "goal type" ball game, is important in that it develops students' teammate co-operation and spatial awareness ("moving and running within a set space"). Fusamae et al. (2001) describes a physical education class which fosters the ability and attitude of each student to improve themselves through the teaching and learning of basketball in a group setting. Murakami et al. (1998) pointed out that although physical strength and technology are also key factors in winning basketball games, the outcome is greatly related to tactics. Therefore, in this class, activities which encourage students to consider tactics are incorporated (related to Cognition of CLIL's 4C). Other reports are found which investigate the relationship between motivation and vitality in junior high school physical education (Nakasuga et al., 2018). Nakasuka et al. emphasize the setting of diverse and challenging short-term goals in physical education classes. It is important to confirm that students understand the impact of a collaborative atmosphere on themselves and their peers (related to Communication and Community of CLIL's 4Cs). In this study, CLIL's 4Cs are deliberately included in basketball instruction to deepen team communication.

\subsection{Qualities and Abilities for CLIL Teachers}

Research on the qualities and competencies required of teachers who perform CLIL classes (CLIL teachers) is advancing mainly in Europe, and various lists and tables have been presented (Coonan, 2018). "CLIL Teachers" should have the ability to teach one or more subjects in the curriculum in languages other than the ones used for regular lessons, and teach the language itself (Eurydice, 2006). Whitty (1996) points out that what CLIL teachers need is "professional awareness", "professional progress and improvement", "communication", "subject knowledge" and "understanding learners and their learning". According to Bertaux et al. (2010) "THE CLIL TEACHER 7S COMPETENCES GRID," CLIL teachers can manage group creation, time management, and class noise using a target language. In addition, using the target language during language learning activities is required even in lesson introduction, explanation, and addressing comprehension difficulties. Furthermore, Papaja (2013) points out the following expectations: (1) language and content should be well integrated in the lesson, (2) lessons should not be overly explanatory, and should give students plenty of time to practice the target language, (3) the native language should not be spoken unless it is deemed necessary, (4) knowledge should be regularly exchanged with other CLIL teachers in other countries, (5) improving the language skills of teachers should be an aim. Pegulescu (2018) states that there is no recipe for becoming a complete teacher and that different teaching skills are required depending on the learner's educational stage. As CLIL teachers are required to develop not only the learner's knowledge of the subject and language skills but also their general abilities, the required pedagogic level is high. In this research, the qualities and abilities necessary for CLIL teachers are considered through a CLIL class which is conducted by teachers of other subjects who do not specialize in English.

\section{Lesson Procedure}

\subsection{Cs and the Lesson Schedule}

Table 1 indicates CLIL's 4Cs in this lesson, while Table 2 indicates the lesson schedule.

Table 1. 4Cs of this CLIL English basketball lesson

\begin{tabular}{ll}
\hline Content & To study the movements involved in basketball \\
& $\begin{array}{l}\text { To think about movements and strategies in basketball games } \\
\text { To learn basketball terms }\end{array}$ \\
\hline Communication & To learn English words and expressions relating to body movements \\
\hline Cognition & To make judgements on how to move during basketball games and practices \\
\hline Culture/Community & $\begin{array}{l}\text { To deepen communication within teams } \\
\text { To know that it is not important which language is used during the basketball practice }\end{array}$ \\
\hline
\end{tabular}


Table 2. Lesson schedule of the basketball CLIL lesson

\begin{tabular}{lll}
\hline & \multicolumn{1}{c}{ Content } & Questionnaires \\
\hline Introductive lesson & Basic movements of basketball & \\
First lesson & English basketball terms & \\
& Strategies in front of the hoop (goal) & Post lesson \\
Second lesson & Review of the previous lesson & questionnares \\
& Game (including team strategy meeting) & \\
& Lesson Review & \\
\hline
\end{tabular}

\subsection{Introductive Lesson}

Students were told that the introduction and the two basketball lessons would be conducted in English. Then the teacher went over the rules, basic movements and vocabulary of basketball.

\subsection{First lesson}

First, the students performed their usual warm-up activities, then they greeted (a formal greeting inherent in Japanese culture which is done for example at the beginning of a class) when the warm-up was over. While using a projector installed in the gymnasium, a teacher explained in English techniques and motivation for basketball improvement (Figure 2, 3).

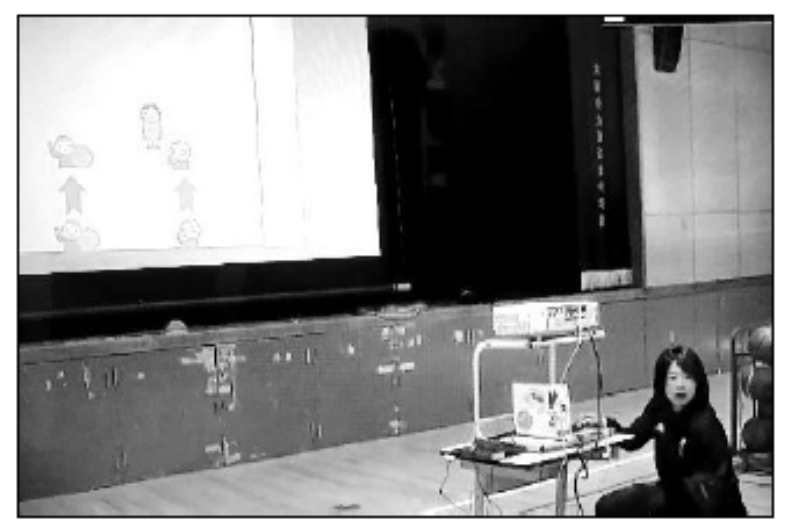

Figure 2. Teacher Talk

(Teacher Talk) "Everyone, let's play basketball in English! Do you like basketball? To be a good basketball player, what do you need to do? You need to practice ... yes, passing, catching, dribbling, and shooting. You have to practice hard to be a good basketball player."

The students answered the questions in English with short answers. They understood that in order to become skilled at basketball, repeated practice in skills such as passing, and shooting was important (Content). For teaching specific movements, the teacher used English basketball terms; for example, how to make a good shot. The teacher advised the students when taking a shot to aim the ball at the upper right or upper left corner of the backboard. The correct timing for a running shot was explained in English (input): run, down, catch, and shoot (Figure 4). Based on the instructions, the students practiced the running shot in groups of three. Taking a shot after receiving a pass from a teammate was also covered in the class. The movement of a layup shot (dribbling the ball while running at high speed toward the opponents' end zone, then when reaching an appropriate distance to the basket catching the ball and taking a shot with one hand in one fluid motion, taking care not to take more steps than is allowed while holding the ball which would result in a penalty) was explained as run, dribble, catch, shoot. Students were advised to shoot with the hand that is closest to the hoop. The teacher also instructed students in the movements (physical skill) of a jump shot (jumping and shooting at the same time - taking care to release the ball when the body reaches the highest point of the jump in order to create height and distance for 
the shot). Next, the teacher used the projector to show a two-pattern strategy of a "2 on 1" practice using the basketball court: a student while running receives a teammate's pass then shoots. The teacher taught English expressions such as pass, run, shoot, and the concepts of offense and defense. The teacher compared the two, indicating to the students that offense is advantageous, requiring quick decision-making skills, therefore regular practice is indispensable. The offense can dribble and shoot if the opposing defense is not in the way. If there is a defender blocking the way to the net, the ball will be passed to a teammate. After passing, the player will always run, ready to accept a pass from a teammate or intercept an opponent's ball. Students then practiced passing and running, shooting, and rebound skills (Cognition).

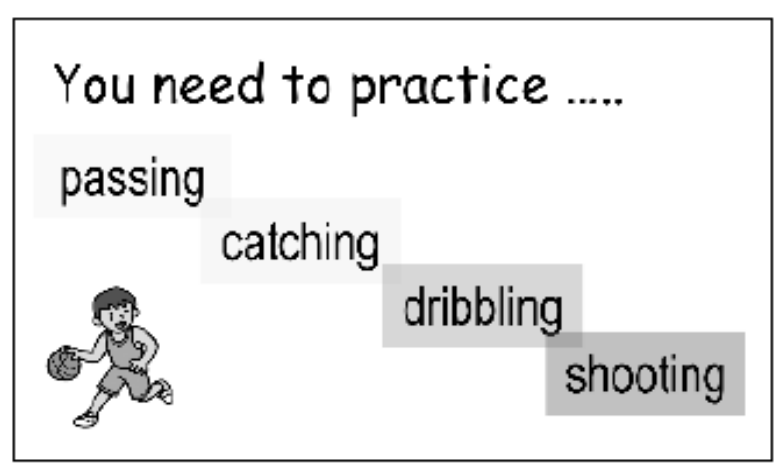

Figure 3.

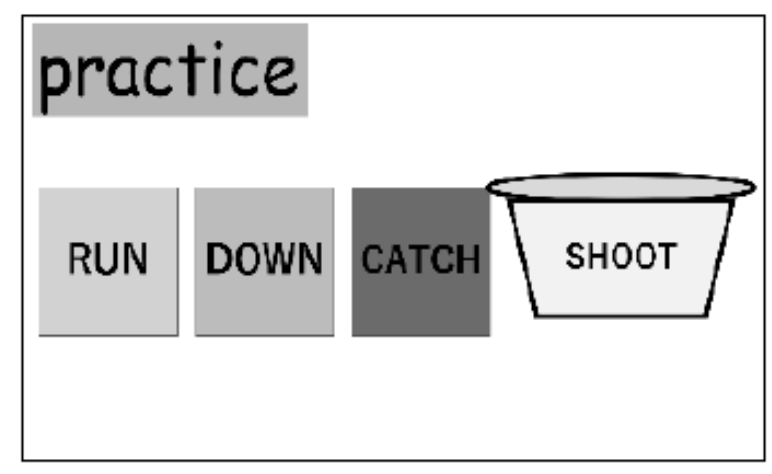

Figure 4.

Slides Used in Class (Basic Movements)

\subsection{The Second Lesson}

With the instruction received in mind, each team played a match-style game after practicing the skills taught.

The students used English actively and practiced hard. The game was a tournament system, and students sometimes had short team meetings to plan strategy. The students used the learned English and played the matches while exchanging advice in English within their teams (Communication, Community). The follow-up instruction and the post questionnaire were conducted in the third lesson. Figures 5 and 6 show examples used to explain the " 2 on 1" in the second half of the first lesson. The students were able to see the ball and people moving on the screen, which helped have an image in their heads of what they were supposed to do when they were playing their actual matches.

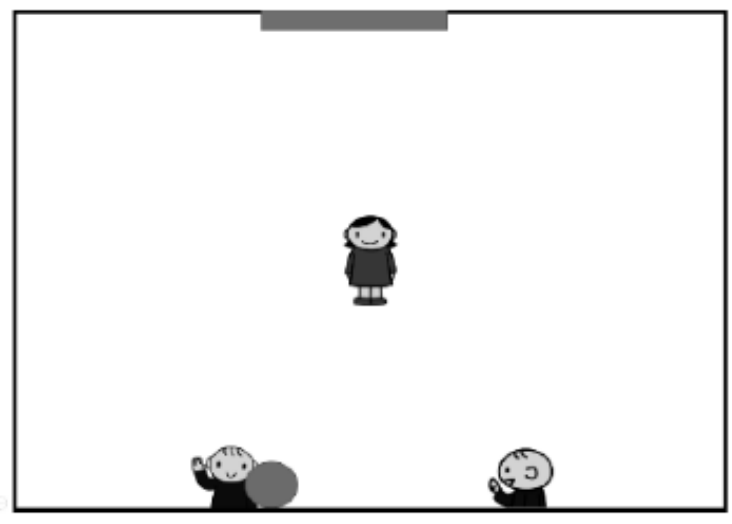

Figure 5.

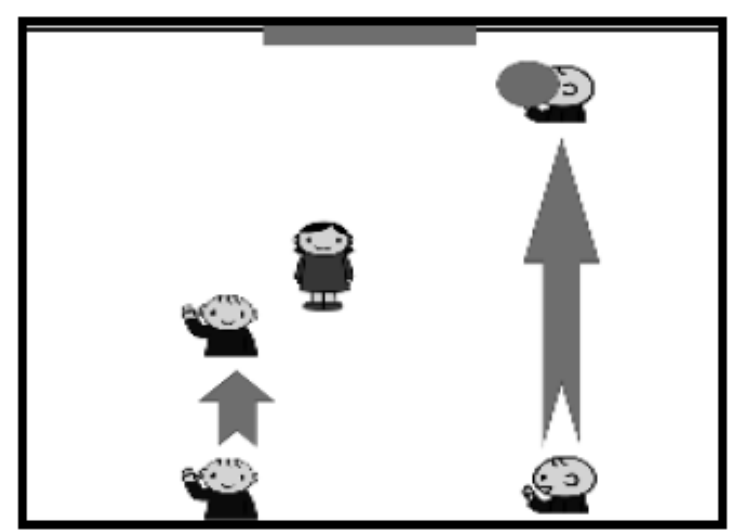

Figure 6.

Slides Used in Class (2 on 1) 


\section{Analysis}

\subsection{Result and Consideration of the Students' Basketball Skills Test}

After the lessons, students took a basketball skills test. The test was comprehensively evaluated for the number of successful shots, the smoothness and correctness of dribbling and passing, and how the students made judgements during matches. As a result, the average score for the entire class was 74.17 and $S D$ was 14.56 (Table 3). Over $80 \%$ of the students understood and learned the basketball movements that were taught. As for English, it was difficult to measure results independently. However, in that over $80 \%$ of the students understood and acquired the basketball skills taught, it can be said that the students had understood the English instruction of the lesson.

Table 3. Descriptive statistics of students' basketball skills test

\begin{tabular}{lcccc}
\hline Task & $n$ & Mean & $S D$ & $S E$ \\
\hline Basketball skill & 23 & 74.17 & 14.56 & 3.03 \\
(shot, pass, dribble, movement, judgements) & & & \\
\hline
\end{tabular}

\subsection{Result and Consideration of the Students' Post Lesson Questionnaire (4 Likert Scale)}

In this chapter, analysis and consideration are conducted based on the students' post lesson questionnaire.

The results are as shown in Tables 4 and 5. All answered positively that the class was fun. The number of students who liked regular English lessons (12 students) was almost the same as the number of students (11 students) who expressed that they did not like them, however the class content was understood (18 students) and basketball terms were learned (20 students). Even students who did not like regular English lessons were able to enjoy and understand the content in English well.

Table 4. Descriptive statistics of students' post lesson questionnaire in the CLIL lesson

\begin{tabular}{lccccc}
\hline Questions & $n$ & Mean & SD & Min & Max \\
\hline Q1 & 23 & 3.48 & 0.51 & 3 & 4 \\
Q2 & 23 & 2.40 & 0.94 & 1 & 4 \\
Q3 & 23 & 2.87 & 0.82 & 1 & 4 \\
Q4 & 23 & 3.13 & 0.76 & 1 & 4 \\
\hline
\end{tabular}

Table 5. Results of students' post lesson questionnaire in the CLIL lesson (number of people)

$n=23$

\begin{tabular}{lcccc}
\hline Questions & $\begin{array}{l}\text { Q1 Did you enjoy } \\
\text { today's basketball } \\
\text { lesson? }\end{array}$ & $\begin{array}{l}\text { Q2 Do you like } \\
\text { regular English } \\
\text { lessons? }\end{array}$ & $\begin{array}{l}\text { Q3 Did you Q4 Did you remember the } \\
\text { understand the } \\
\text { lesson content } \\
\text { in English? }\end{array}$ & $\begin{array}{l}\text { Qnglish basketball terms? } \\
\text { 4: strongly agree }\end{array}$ \\
3: agree & 11 & 2 & 4 & 7 \\
2: disagree & 0 & 10 & 14 & 13 \\
1: strongly disagree & 0 & 6 & 3 & 2 \\
\hline
\end{tabular}

\subsection{Results and Discussion of Descriptive Questionnaire}

In the questionnaire, there were questions about the lessons that could be answered freely. Table 6 shows the frequency each word occurred in students' answers. Looking at the number of positive words, it can be said that students had fun during the lessons. 
Table 6. Word frequency list by part of speech

$n=23$

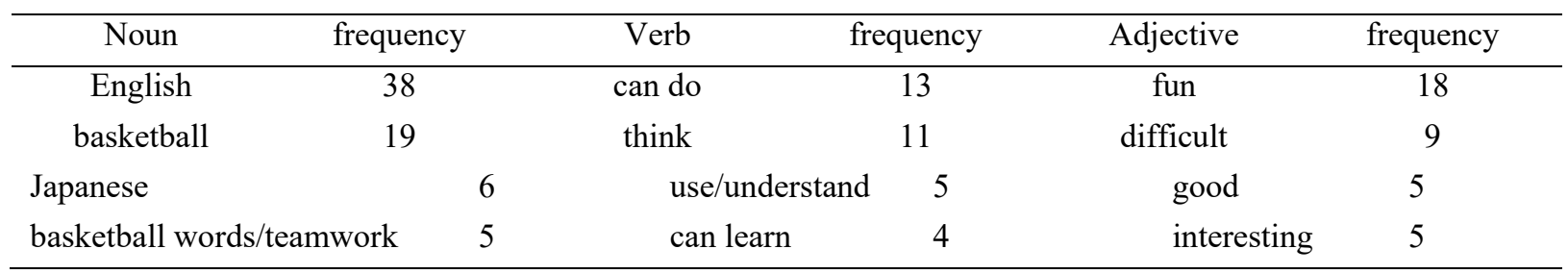

Q5 What did you learn in this lesson? The students' learning was considered through analyzing the relationship of words extracted from students' questionnaires. Figure 7 is a co-occurrence network diagram. The students' post-lesson questionnaires were translated by the author. In the co-occurrence network diagram, the size of the circle represents the number of words used. Groups are regarded as strong co-occurrence terms and meaning is interpreted based on those terms. From this figure 7, in terms of area size, "English", "basketball", "difficult", and "learn" are key words. Although "English" and "difficult" are directly linked, it is thought that students are very conscious of English. In addition, "play (basketball)" leads to "fun", and "team play" is "important" for "communication". As shown in the previous research, in basketball classes the collaborative atmosphere greatly influences the students. It can be said that in this lesson the team was able to deepen communication. In addition, they think it was necessary to "consider (think) more" than "usual Japanese classes". It is interesting that the "language" of English is directly linked to "difficult", "consider", "understand", and "speak". Through the quantitative research, the students felt that the class was fun, however, through qualitative research it can also be understood that the students were conscious of what they were doing in English. They enjoyed the lessons and learned a lot. This is the depth and attraction of CLIL. In this CLIL lesson, it is important to use language other than that which is generally used in "English conversation learning" and to delve deeply into the content to develop game tactics together as a team.

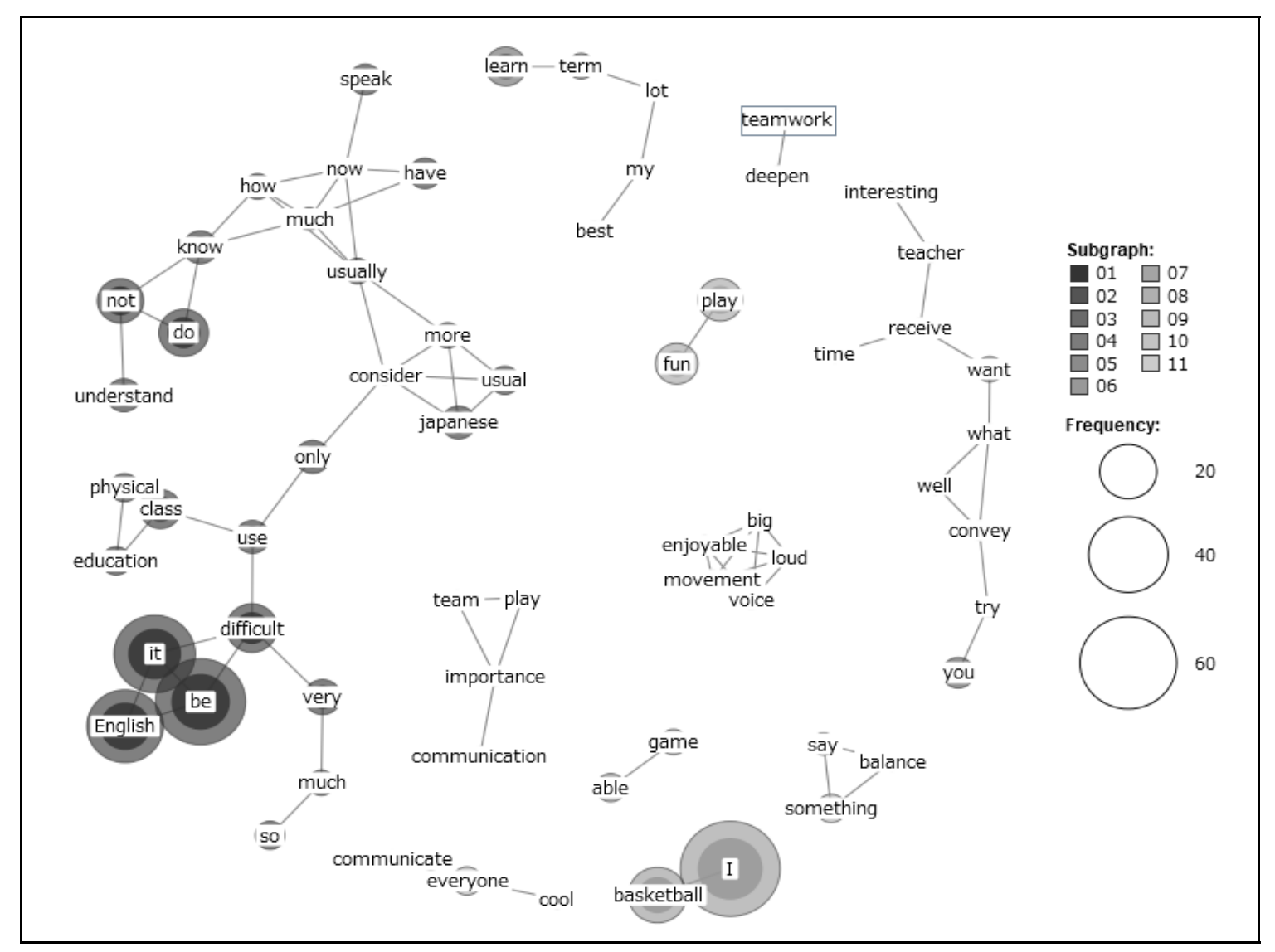

Figure 7. Co-Occurrence Network Diagram of Post Lesson Questionnaire 


\subsection{Result and Consideration of Teacher's Pre and Post Lesson Interview}

In this study, before and after the three lessons, the teacher was given two semi-structured interviews, each about 60 minutes in length. The teacher was asked about expectations and concerns about teaching a CLIL lesson in the pre lesson interview. In the post-lesson interview, class development, lesson results, students' reactions, and the possibilities and concerns about teaching CLIL in the future were covered. The interviews were firstly generated in scripts and analyzed qualitatively based on the SCAT analysis. The pre and post story lines and theories are described below through SCAT's four-step coding process and its handling of themes and constructs (Table 7, 8).

Table 7. Teacher interviews on the CLIL lesson (pre)

\begin{tabular}{|c|c|c|c|c|c|}
\hline No & Text & $\begin{array}{l}\text { (1) focused } \\
\text { words from } \\
\text { within the text }\end{array}$ & $\begin{array}{l}\text { (2) words } \\
\text { outside of the } \\
\text { text }\end{array}$ & $\begin{array}{l}\text { (3) words } \\
\text { explain the } \\
\text { words in } 1,2\end{array}$ & $\begin{array}{l}\text { (4) Themes \& } \\
\text { constructs }\end{array}$ \\
\hline 1 & $\begin{array}{l}\text { I did not know anything about } \\
\text { CLIL until I heard about it through } \\
\text { this research. In fact, I do not have } \\
\text { confidence in English. I can speak } \\
\text { if I prepare it in advance, but my } \\
\text { pronunciation is not as clear as an } \\
\text { English teacher, so I'm afraid } \\
\text { students won't be able to } \\
\text { understand my English. }\end{array}$ & $\begin{array}{l}\text { I am not } \\
\text { confident in } \\
\text { English } \\
\text { Pronunciation } \\
\text { is not as clear } \\
\text { as an English } \\
\text { teacher }\end{array}$ & $\begin{array}{l}\text { Not confident } \\
\text { in English } \\
\text { Anxiety about } \\
\text { pronunciation }\end{array}$ & $\begin{array}{l}\text { English } \\
\text { language } \\
\text { skills of } \\
\text { teacher's } \\
\text { Japanese } \\
\text { accent }\end{array}$ & $\begin{array}{l}\text { Anxiety for } \\
\text { English ability }\end{array}$ \\
\hline 2 & $\begin{array}{l}\text { I think that the students will } \\
\text { probably become bright in their } \\
\text { mood and try to use English } \\
\text { actively. It is not obvious if } \\
\text { students have physical education } \\
\text { skills or not. I'm looking forward to } \\
\text { having effective lessons that make } \\
\text { students more interested than usual. }\end{array}$ & $\begin{array}{l}\text { Become bright } \\
\text { in mood and } \\
\text { try to use } \\
\text { English } \\
\text { positively } \\
\text { Looking } \\
\text { forward to } \\
\text { having } \\
\text { effective } \\
\text { lessons }\end{array}$ & $\begin{array}{l}\text { Feel better } \\
\text { Unusual class }\end{array}$ & $\begin{array}{l}\text { Atmosphere } \\
\text { of class } \\
\text { Mannerism } \\
\text { A mood that } \\
\text { makes it easy } \\
\text { to talk }\end{array}$ & $\begin{array}{l}\text { Positive } \\
\text { interesting class }\end{array}$ \\
\hline 3 & $\begin{array}{l}\text { Students may be able to learn } \\
\text { basketball terms in English, } \\
\text { increase team communication, and } \\
\text { make it easier to speak in English. }\end{array}$ & $\begin{array}{l}\text { Remember } \\
\text { terms in } \\
\text { English } \\
\text { More } \\
\text { communication } \\
\text { It becomes } \\
\text { easy to talk }\end{array}$ & $\begin{array}{l}\text { Atmosphere } \\
\text { easy to speak } \\
\text { in English }\end{array}$ & $\begin{array}{l}\text { Know what } \\
\text { you don't } \\
\text { know } \\
\text { Don't need } \\
\text { to mind if } \\
\text { make } \\
\text { mistake }\end{array}$ & $\begin{array}{l}\text { Specific } \\
\text { expression of } \\
\text { subject } \\
\text { Communication }\end{array}$ \\
\hline 4 & $\begin{array}{l}\text { However, I am worried that } \\
\text { students might be distracted by } \\
\text { English and become less aware of } \\
\text { learning basketball skills. Also, } \\
\text { students who do not like English } \\
\text { may not be following the lesson. In } \\
\text { English, it may be difficult to ask } \\
\text { the teacher questions, or the } \\
\text { explanation may become long until } \\
\text { teacher gets used to it. }\end{array}$ & $\begin{array}{l}\text { Distracted by } \\
\text { English, } \\
\text { Become less } \\
\text { aware of } \\
\text { learning skills } \\
\text { Hard to ask the } \\
\text { teacher } \\
\text { questions }\end{array}$ & $\begin{array}{l}\text { Physical } \\
\text { education } \\
\text { skills } \\
\text { Understanding } \\
\text { the content }\end{array}$ & $\begin{array}{l}\text { Basketball } \\
\text { movement } \\
\text { Flow of time } \\
\text { Time } \\
\text { allocation }\end{array}$ & $\begin{array}{l}\text { Basketball } \\
\text { techniques } \\
\text { Class tempo }\end{array}$ \\
\hline
\end{tabular}

The following story line was constructed about how the teacher felt about the CLIL basketball lesson.

Pre story line: The teacher is anxious about taking on the challenge of an English CLIL lesson, but also expects that the students will be interested in the lesson. Students will be able to communicate easily in English. However, there is a concern about whether students will become interested in speaking in English and be able to acquire basketball skills. That is difficult. The teacher is looking forward to the CLIL lesson. 
The theoretical description written based on this is as follows:

- Anxious about English but also has expectations of the CLIL lesson.

- The CLIL lesson will involve the students in the English atmosphere and they will be able to communicate easily.

- There is a concern about whether students can become interested in speaking in English and acquire basketball skills.

Table 8. Teacher interviews on the CLIL lesson (post)

\begin{tabular}{l} 
No 1 Text \\
\cline { 2 - 2 } 1 I spoke in English as much as possible \\
and used simple English words when it \\
was difficult for students to \\
understand. When I asked the students \\
to use English as much as possible in \\
the class, they were trying to talk in \\
English.
\end{tabular}

2 It was difficult to answer in English immediately when asked questions from students. I wondered how to express words I do not know.

3 Students who liked English were motivated by listening and speaking in English, and students who liked physical education were motivated by the appeal to their physical skills. They were more motivated to study than regular English and physical education lessons.

$4 \quad$ Group behavior movements and words are not familiar in English, so it may be difficult for a series of movements in classes such as "alignment","bow" "right for right" "Attention", etc.

5 It has become an atmosphere that makes it easier for students to actively challenge physical education skills. The students were eager to use English. They want to use it, but they do not know how to use it.

6 As for technical matters, no dramatic change was felt in only 2 hours of lessons, but the motivation was high. Even during the game, quite a few voices could be heard, and their communication was better than the regular classes.

(1) focused
words from
within the text
English as
much as
possible,
Students try to
talk in English.

Difficult to answer in English quickly

More motivated to learn than regular English and P.E. classes

Group behavior movements and words are not familiar

\section{Atmosphere} that makes it easier to actively challenge basketball skills

Motivated, Communication was better than the regular classes

(2) words
outside of
the text
$\begin{aligned} & \text { Teaching in } \\ & \text { English }\end{aligned}$
Teacher's
language
skills,
anxiety

(3) words explain the words in 1,2

Teaching in

English

only, learning rules, acceptance, inclusion

Take advantage of the favorite subject, motivation

\section{Drawers of} words, rich expresson, annoyance, worry

\section{Effect on} the willingness to learn for both subjects

Expression of "order" in English

\section{Specific} expression of subject, rules

The spirit of challenge, feeling that they want to use English

Motivation,

Friends relationship

Higher motivation

Good teamwork

Positive, motivation, excitement
(4) Themes \& constructs

All English

Environment language skills

synergistic effects

English expression of subject Eager to speak ambitious, English

Willingness to learn, Communication 
Post story line: In order to create an all-English environment, the teacher tried to speak to the students in English as much as possible, and the students also began to speak in English. It was difficult for the teacher to answer in English when suddenly asked questions. The teacher felt that it is necessary to improve her language skills. English is simpler than Japanese, and while it is easy to use in exercise situations, English expressions such as "alignment" or "bow" are not familiar in Japanese schools. Students have a desire to speak in English. In physical education classes, they learned English expressions specific to subject content. This lesson can be effective for both students who like English and students who like physical education and a synergistic effect can be expected.

The theoretical description written based on this is as follows.

-By teaching in an all-English environment, not only teachers but also students will use English.

-A CLIL lesson where physical education is performed in English is effective for both students who like English and students who like physical education.

-Is there effective support for students who want to use English but do not know how to use it?

-With regard to English language ability, it may be possible to eliminate anxiety by further improving the teacher's own language ability.

Looking at the transformation from the pre and post lesson interview, the students enjoyed the atmosphere of English and were communicating in English as the teacher expected. The students were louder than usual. They learned basketball terms and learned strategies and movements. The teacher realized that CLIL had a strong effect, as the motivation of the students was higher than usual. However, English expressions such as alignment and gratitude are said to be unfamiliar in Japanese schools. In English, "fall in" is to form lines, "face right" is to turn to the right, and "attention" is stand up straight. However, because these English expressions are not often used in schooling, it is assumed that students were unfamiliar with them.

\section{Results and Discussion}

In this study, CLIL instruction in basketball was given to a girls's junior high school second grade physical education class. The students' learning in the CLIL lesson was considered through the post lesson questionnaire and the pre and post lesson interviews of the teacher. From the post lesson questionnaire, it was found that the students enjoyed the class, understood the content in English, and learned English expressions and English basketball terms. The students felt that English was difficult but interesting, and that they could deepen their teamwork in English. Furthermore, there were many students who did not particularly like English but experienced the CLIL class of basketball as fun. Even students who were not confident in English retained the expression taught to them, and they also felt that they wanted to use English. From that it was recognized that CLIL was effective.

From the pre and post lesson interviews with the teacher it was seen that the students enjoyed listening and speaking in English and were communicating better than the teacher expected. The students were able to create an English-speaking environment by consciously using English. Some students liked English and others liked physical education, however during the CLIL lessons, the teacher felt that both groups were able to participate with confidence. In addition, raising the English ability of the teacher and the students who want to use English but do not know enough to understand the scene or the appropriate expressions is a future task for the education system. During the class activities, students often used English, but also used their mother language. However, in these lessons, students learned to use subject-specific basketball terms in English and often spoke in English. There is a further point which calls for discussion: the English words for expressions often used in Japanese physical education classes such as "face right" or "fall in" seemed to be unfamiliar in Japanese schools. It may be better to use these expressions as they are in Japanese. Instead of using all English expressions, the native language can be used effectively depending on the situation. The students actively wanted to use English and were able to participate in classes in a good atmosphere of playing basketball while using easy-to-understand, easy-to-use English expressions. Junior high school students are still beginners at learning English and will be able to speak more in English as they progress in their secondary school careers. It was meaningful to be able to listen and understand each lesson in English and think and speak in English by themselves. As shown in the previous research, CLIL teachers are required to "progress and improve professionally," "communicate," and "understand learners and their learning processes". In this lesson, teachers with such skills were able to devise a CLIL lesson for students to acquire physical education skills and English expressions and usage in actual situations. Even though the teacher did not specialize in English, it was possible to proceed smoothly by teaching in advance the expressions to be used. As teachers can experience difficulty responding in English to sudden 
questions, it is necessary to predict possible questions and devise answers to those questions in advance.

In this lesson, $21^{\text {st }}$ century skills necessary for future success along with the improvement of physical fitness and motivation aimed toward global education in conjunction with the lesson content. As a result, the students were able to understand English and learn basketball terms and strategies. Furthermore, they not only learned them, but they also tried to work with teachers and their peers, resulting in a positive and successful class. The students learned a great amount from these three lessons. It is needed to continue CLIL practices in various subjects in the future and to support a change of attitude and motivation toward English learning.

\section{Acknowledgments}

This work was supported by JSPS KAKENHI Grant Number JP17H07274. Thank you very much for Ms. Hoshimi Kaori, and Lee Shizuka, teachers, and students in Sumiegaoka Elementary School, Osaka, Japan.

\section{References}

Anderson, L. W., \& Krathwohl, D. R. (Eds.). (2001). A taxonomy for Learning, Teaching and Assessing: A Revision of Bloom's Taxonomy of Educational Objectives: Complete edition. New York: Longman

Bertaux, P., Coonan, C. M., Frigols-Martin, M. J., \& Mehisto, P. (2010). THE CLIL TEACHER'S COMPETENCES GRID. Rwehttp://tplusm.net/CLIL_Competences_Grid_31.12.09.pdf

Bloom, S. B. (1956). Taxonomy of educational objectives book 1: Cognitive Domain The classification of educational goals (1st ed.). Harlow, Essex, England: Longman Group.

Coonan, C. M. (2018). CLIL Teacher Education: Challenges and directionality. Language Teacher Education, 5(1), 1-13.

Coyle, D., Hood, P., \& Marsh, D. (2010). CLIL: Content and Language Integrated Learning. Cambridge: Cambridge University Press.

Eurydice. (2006). Content and Language Integrated Learning at School in Europe. Brussels: Eurydice European Unit.

Fujiwara, M. (2013). Practice about "how to use space" in the lesson of basketball. Research Journal of Sport Science in Nara Women's University, 15, 79-82.

Fusamae, K., Okamoto, M., Miyake, Y., Fujimoto, T., Takata, M., Miyake, A., Fujiwara, H., \& Esashi, Y. (2001). Physical Education Class to Bring up Zest for Living: Basketball that Each Student Works Independently. Bulletin of theory and practice in secondary education/ Fukuyama Junior and Senior High School Attached to Hiroshima University, 41, 89-98.

Higuchi, K. (2014). Metric Text Analysis for Social Survey: Toward Succession and Development of Content Analysis. Tokyo: Nakanishiya Shuppan.

Ikeda, M. (2017). Model construction of translanguaging in CLIL. English Literature and Language, 53, 1-12.

Ikeda, M. (2018). A secret to dramatically improve "Inactive English for exams". TOYO KEIZAI ONLINE. from https://toyokeizai.net/articles/-/228275?page=3

Ito, Y. (2018). CLIL in Practice in Japanese Elementary Classrooms: An Analysis of the effectiveness of a CLIL Lesson in Japanese Traditional Crafts. English Language Teaching, 11(9), 59-67. https://doi.org/ 10.5539/elt.v11n9p59

Kashiwagi, K., \& Tomecsek, J. (2015). How CLIL classes exert a positive influence on teaching style in student centered language learning through overseas teacher training in Sweden and Finland. Procedia, 173, 79-84. https://doi.org/10.1016/j.sbspro.2015.02.034

Kudo, T. (2018). An attempt to activate learners' higher-orderthinking skills through CLIL lessons dealing with global issues, Nagoya Gakuin University Ronshu Language. Culture, 29(2), 39-50.

Ministry of Education, Culture, Sports, Science and Technology (MEXT). (2012). Hi, friends!. Tokyo: Tokyo Shoseki.

Ministry of Education, Culture, Sports, Science and Technology (MEXT). (2017). Course of Study: Foreign Language Activities, foreign Languages. Tokyo: Kairyudo.

Murakami, K., Mino, T., Yamamoto, T., Kawata, K., Aoki, A., \& Beniya, M. (1998). Development of practice contents from the viewpoint of game analysis in basketball (physical education method). The $49^{\text {th }}$ Japanese Society of Physical Education, 528. https://doi.org/10.20693/jspeconf.49.0_528 
Muranoi, H. (2006). Effective English Learning and Teaching Methods from the Perspective of Second Language Acquisition Research, Tokyo: Taishukan Shoten.

Nakasuga, T., Sakata, S., \& Sugiyama, Y. (2018). Assessment of causal relationships between motivational climates, goal orientations and "Zest for Living" in junior high school physical education classes. Japan J. Phys. Educ. Hlth. Sport Sci, 63(1). https://doi.org/10.5432/jjpehss.17104

National Institute for Educational Policy Research. (2013). Basic principles of curriculum formation to foster the qualities and abilities that respond to social changes. 2012 project research survey research report. https://www.nier.go.jp/kaihatsu/pdf/Houkokusho-5.pdf

Nishijima, N., Suzuki, K., Koyama, H., Kawaguchi, C., \& Komatsuzaki, S. (2000). Causal structure analysis on promotion process of initiative problem-solving ability in Physical Education program in junior high school. Japan J. Phys. Educ. Hlth. Sport Sci, 45(3), 347-359. https://doi.org/10.5432/jjpehss.KJ00003397610

Otani, T. (2011). SCAT: Steps for Coding and Theorization: Qualitative data analysis method with explicit procedure, easy to set about, suitable for small scale data. Kansei Engineering, 10(3), 155-160.

Papaja, K. (2013). The role of a teacher in a CLIL classroom: Focus on CLIL: A qualitative Evaluation of Content and Language Integrated Leaning in Polish Secondary Education, CAMBRIDGE SCHOLARS PUBLISHING, 148.

Pegulescu, A. M. (2018). (Nakayama, N. \& Daigo, M., Trans.) (Hisamura, K., Rev.). World-wide EPOSTL: The case of Romania. Language Teacher Education, 5(1), 15-26.

Sasajima, S. (2011). CLIL: New Ideas for Classes. Tokyo: Sanshusha.

Watanabe, Y, Ikeda, M., \& Izumi, S. (Eds.) (2011). CLIL: New Challenges in Foreign Language Education, 1. Tokyo: Sophia University Press. https://doi.org/10.1175/2010JCLI3878.1

Whitty, G. (1996). Creating Quasi-Markets in Education: A review of recent research on Parental choice and school autonomy in three countries. Review of Research in Education, 22, 89-95. https://doi.org/10.2307/ 1167373

Yamano, Y. (2013). Utilizing the CLIL approach in Japanese primary school: A comparative of CLIL and EFL Lessons. The Asian EFL Journal, 15(4), 160-183.

\section{Copyrights}

Copyright for this article is retained by the author(s), with first publication rights granted to the journal.

This is an open-access article distributed under the terms and conditions of the Creative Commons Attribution license (http://creativecommons.org/licenses/by/4.0/). 